Gut, 1977, 18, 1021-1026

\title{
Pathophysiology of hypotension in patients with fulminant hepatic failure
}

\author{
P. N. TREWBY AND ROGER WILLIAMS \\ From the Liver Unit, King's College Hospital and Medical School, London
}

SUMMARY Studies on the incidence and pathophysiology of hypotension in fulminant hepatic failure showed that 82 out of 94 patients developed arterial hypotension with a systolic blood pressure of less than $80 \mathrm{mmHg}$. Such episodes accounted for $16 \%$ of the total time spent in grade IV coma. Factors such as haemorrhage, cardiac or respiratory abnormalities, extracorporeal perfusion, or hypotension which occurred during the terminal stages of the illness, could be implicated for only $40 \%$ of this time, leaving $60 \%$ as unexplained. Further investigation of these unexplained factors showed that peripheral vasodilatation rather than primary heart failure was responsible, and in all but three patients construction of ventricular function curves showed a normal ventricular response to volume expansion with a corresponding increase in blood pressure. A small, but significant, slowing of the heart rate occurred during these periods of unexplained hypotension. This, together with the association that was found between the occurrence of hypotension and cerebral oedema with coning, suggests that central vasomotor depression may be important in its pathogenesis.

Although the occurrence of hypotension in fulminant hepatic failure is well recognised (Ritt et al., 1969; Rueff and Benhamou, 1973), there is little published information concerning its pathogenesis or even its frequency. Its importance lies in the secondary hypoxic brain damage that may ensue from the associated reduction in cerebral blood flow and cerebral oxygen delivery. The present analysis is based on a series of 94 patients in whom we have documented the total duration of the hypotension, its significance in relation to the patient's clinical course, and the apparent factors underlying it. Particular attention has been paid to those patients in whom hypotension could not be explained on the basis of blood loss, respiratory difficulties, or cardiac arrhythmias. The cardiac output and indirect left atrial pressure have been measured in these patients and ventricular function curves constructed to determine the relative roles of heart failure and peripheral vasodilatation. The possibility of a central origin for the hypotension, perhaps related to the cerebral oedema which appears so frequently in this condition, was also investigated (Gazzard et al., 1975).

\section{Methods}

The 94 patients were admitted to the Liver Failure

Received for publication 30 May 1977
Unit between 1974 and 1976, and all of them had deteriorated to grade IV coma (Trey and Davidson, 1970) by the time of investigation. Aetiology of fulminant hepatic failure included $\mathrm{HBs} A g$ negative hepatitis (28 patients), HBsAg positive hepatitis (11), paracetamol overdose (42), and 13 patients with miscellaneous causes, including anaesthetic and drug reactions, fatty liver of pregnancy, and Amanita phalloides toxicity. The patients were treated with standard supportive therapy which included $10 \%$ dextrose infusions, oral lactulose, magnesium sulphate enemata, and vitamin supplements. In addition, 52 of them received temporary liver support, 42 by perfusions of whole blood through activated charcoal for a period of four hours daily (Gazzard et al., 1974), and 10 by haemodialysis using a polyacrylonitrile membrane and a RhonePoulenc dialyser (RP6) (Silk et al., 1977) for a period of four to eight hours daily.

Plasma electrolyte and arterial blood gas concentrations and liver and renal function were measured at least once a day, and blood, urine, and, where possible, sputum were cultured daily. A central venous pressure line was inserted on admission and its position was checked radiographically. The pulse, blood pressure, respiratory rate, and central venous pressure (cm water from the sternal angle), as well as the clinical condition of the patient were then recorded every hour.

Hypotension was defined as a systolic blood 
pressure of less than $80 \mathrm{mmHg}$ lasting longer than one hour. Patients were grouped according to whether hypotension had occurred after haemorhage, a respiratory arrest or episode of hypoxaemia, a cardiac arrest or cardiac arrhythmia, or in association with extracorporeal perfusion, or whether it had started only in the last 12 hours of life. Hypotension in the remaining cases was classed as 'unexplained'.

\section{CIRCULATORY ASSESSMENT}

The cardiac output was measured in the first four patients using dye dilution with indocyanine green (Hamilton, 1962), and in the subsequent 12 patients using thermodilution with a Swan-Ganz thermodilution catheter (Ganz and Swan, 1962). The mean of three readings for the cardiac output was taken, and the cardiac index calculated from the equation:

Cardiac index $\left(1 \mathrm{~min}^{-1} \mathrm{~m}^{-2}\right)=$

$$
\frac{\text { cardiac output }\left(1 \mathrm{~min}^{-1}\right)}{\text { body surface area }\left(\mathrm{m}^{2}\right)}
$$

The indexed systemic peripheral resistance was derived from the equation:

Indexed systemic peripheral resistance (dyne. $\mathrm{s} \mathrm{cm}^{-5}$ $\left.\mathrm{m}^{-2}\right)=$

$$
\frac{\text { Mean blood pressure }(\mathrm{mmHg}) \times 80}{\text { Cardiac index }\left(1 \mathrm{~min}^{-1} \mathrm{~m}^{-2}\right)}
$$

(Wood, 1956), where mean blood pressure $=$ diastolic blood pressure $+1 / 3$ pulse difference. The indirect left atrial pressure was measured using a flow-directed, balloon-tipped catheter (Ganz and Swan, 1962), and the effect of rapid infusion of $500 \mathrm{ml}$ of fresh frozen plasma on the indirect left atrial pressure and cardiac output was determined in selected patients. The left ventricular stroke work index was calculated in these patients before and after fluid infusion from the formula:

Left ventricular stroke work index $=$

Cardiac index $\times$ mean blood pressure $\times 13.5 \mathrm{gmm}^{-2}$

Heart rate $\times 1000$

(Carey et al., 1967). The two values for left ventricular stroke work index for each patient were plotted against the indirect left atrial pressure to obtain the ventricular function curve. The effects of five minute infusions of isoprenaline $(10 \mathrm{mg} / \mathrm{min})$ and dopamine $(120 \mathrm{mcg} / \mathrm{min})$ on left ventricular function were also studied in one patient.

\section{Results}

Hypotension was recorded on at least one occasion in 82 of the 94 patients while they were in grade IV coma. Each patient had two episodes of hypotension on average (range one to four), and spent a mean of 18.8 hours with a systolic blood pressure of less than $80 \mathrm{mmHg}$. This represented $16.3 \%$ of the total time in grade IV coma (Table 1). When the time spent hypotensive was analysed according to the most likely cause, only $25 \%$ could be accounted for on the basis of either haemorrhage, hypoxia, respiratory arrest, cardiac arrhythmia, or cardiac arrest. Four per cent could be explained on the basis of extracorporeal haemoperfusion and of the 19 patients with this complication it was the only cause of the hypotension in five, and in the remaining 14 it represented the first episode of hypotension. A further $11 \%$ of the time spent hypotensive could be accounted for by those episodes of hypotension which developed during the last 12 hours of life. The remaining $60 \%$ of the total time could therefore not be explained on the basis of the above factors. Individual consideration of the patients showed that in 56 of the 94 there were one or more episodes of unexplained hypotension, their average total duration being 17 hours, which represented $15 \%$ of the total time that each of the 56 patients spent in grade IV coma. Only four of these 56 patients survived to leave hospital, while 11 of the 38 not developing episodes of unexplained hypotension made a complete recovery $\left(\chi^{2}=6.48, \mathrm{P}<0.02\right)$. Hypotension due to known causes was also associated with a bad prognosis, with only two of these 20 patients surviving, compared with nine of 18 who remained normotensive throughout their illness, or in whom hypotension developed only terminally $\left(\chi^{2}=5.55, \mathrm{P}<0.05\right)$

There was no evidence to implicate fluid depletion in the pathogenesis of the unexplained episodes of hypotension, as, during the 24 hours before its development, the mean positive fluid balance for these patients was $1288 \mathrm{ml}$, and only three of the patients had been maintained in a negative fluid balance because of previous fluid overload or a high central venous pressure. Infection could not be implicated either, for in only three patients was there bacteriological evidence of infection at the time of the fall in blood pressure.

The maximum prolongation of the prothrombin time, which was taken as an indication of the severity of liver damage, was found to be significantly longer in those patients with unexplained hypotension than in those who either remained normotensive throughout their illness or in whom the development of hypotension had been precipitated by known factors, the mean values being $98 \pm 6$ seconds and $68 \pm 5$ seconds respectively (mean \pm 1 SEM, $\mathbf{P}<0.001$ ). There was no difference in the severity of renal failure in those with unexplained hypotension as compared with those without, the mean values for serum creatinine being 
Table 1 Percentage of total time in grade IV coma spent hypotensive in relation to most likely cause of hypotension and aetiology of fulminant hepatic failure

\begin{tabular}{|c|c|c|c|c|c|c|c|}
\hline \multirow{2}{*}{$\begin{array}{l}\text { Aetiology of fulminant } \\
\text { hepatic failure } \\
\text { (no. of patients) }\end{array}$} & \multicolumn{6}{|c|}{ Cause of hypotension } & \multirow{2}{*}{$\begin{array}{l}\text { Total } \% \text { of time } \\
\text { spent hypotensive }\end{array}$} \\
\hline & $\begin{array}{l}\text { Bleeding } \\
(\%)\end{array}$ & $\begin{array}{l}\text { Hypoxia or } \\
\text { respiratory } \\
\text { arrest } \\
(\%)\end{array}$ & $\begin{array}{l}\text { Cardiac } \\
\text { arrhythmia } \\
\text { or cardiac } \\
\text { arrest } \\
(\%)\end{array}$ & $\begin{array}{l}\text { Extra- } \\
\text { corporeal } \\
\text { haemo- } \\
\text { perfusion } \\
(\%)\end{array}$ & $\begin{array}{l}\text { Terminal } \\
\text { (last } 12 \\
\text { hours of } \\
\text { life }) \\
(\%)\end{array}$ & Unexplained & \\
\hline $\begin{array}{l}\text { Hepatitis HBsAg-negative (28) } \\
\text { Hepatitis HBsAg-positive (11) } \\
\text { Paracetamol overdose (42) } \\
\text { Miscellaneous (13) } \\
\text { Total (94) }\end{array}$ & $\begin{array}{l}2 \cdot 1 \\
0 \\
3 \cdot 6 \\
0 \\
2 \cdot 0\end{array}$ & $\begin{array}{l}1 \cdot 2 \\
2 \cdot 7 \\
3 \cdot 1 \\
0 \\
2 \cdot 0\end{array}$ & $\begin{array}{l}0 \cdot 1 \\
0 \\
0 \cdot 2 \\
0 \\
0 \cdot 1\end{array}$ & $\begin{array}{l}0.4 \\
1 \cdot 0 \\
1 \cdot 1 \\
1 \cdot 5 \\
0.7\end{array}$ & $\begin{array}{l}1 \cdot 0 \\
1 \cdot 0 \\
3 \cdot 0 \\
2 \cdot 1 \\
1 \cdot 8\end{array}$ & $\begin{array}{r}7 \cdot 2 \\
7 \cdot 6 \\
12 \cdot 9 \\
10 \cdot 4 \\
9 \cdot 7\end{array}$ & $\begin{array}{l}12 \cdot 0 \\
12 \cdot 3 \\
23 \cdot 9 \\
14 \cdot 0 \\
16 \cdot 3\end{array}$ \\
\hline
\end{tabular}

$0.43 \pm 1$ SEM 0.04 and $0.38 \pm 1$ SEM $0.90 \mathrm{mmol} / \mathrm{l}$ respectively.

\section{HAEMODYNAMIC CHANGES DURING UNEX-} PLAINED HYPOTENSION

There was no consistent evidence of heart failure in the 56 patients with unexplained hypotension. Thus, serial measurements of central venous pressure gave a mean value of $2 \cdot 1 \mathrm{~cm} \mathrm{H} \mathrm{H}_{2} \mathrm{O}$ immediately before the onset of hypotension and $0.82 \mathrm{~cm} \mathrm{H}_{2} \mathrm{O}$ afterwards. The mean cardiac index measured in 16 patients during an episode of unexplained hypotension was $3.32 \pm 1$ SEM $0.301 \mathrm{~min}^{-1} \mathrm{~m}^{-2}$, which was within the accepted normal range (Doyle et al., 1953) $(3 \cdot 2 \pm 2$ SD $0 \cdot 4)$, and this was reduced in only three of the hypotensive patients (Table 2). In two of the five patients in whom it was measured both before and during the period of hypotension, the cardiac output actually increased (Fig. 1), whereas in all five patients the derived peripheral resistance fell. An unexpected observation was that with the development of hypotension the heart rate fell

Table 2 Haemodynamic parameters in normotensive patients and in patients with unexplained hypotension

\begin{tabular}{|c|c|c|c|}
\hline & $\begin{array}{l}\text { Normotensive } \\
\text { patients } \\
(n=13)\end{array}$ & $\begin{array}{l}\text { Hypotensive } \\
\text { patients } \\
(n=16)\end{array}$ & $\begin{array}{l}\begin{array}{l}\text { Normal } \\
\text { values }\end{array} \\
\text { (mean } \pm \\
\text { I SEM) }\end{array}$ \\
\hline \multirow{3}{*}{$\begin{array}{l}\text { Cardiac index } \\
\left(1 \mathrm{~min}^{-1} \mathrm{~m}^{-2}\right) \\
\text { Indexed peripheral } \\
\text { resistance } \\
\left.\text { (dyne } \mathrm{cm}^{-5} \mathrm{~m}^{-2}\right) \\
\text { Systolic blood } \\
\text { pressure }\end{array}$} & $\begin{array}{l}4.33 \pm 0.28 \\
P=<0.001\end{array}$ & $\begin{array}{l}3 \cdot 32 \pm 0 \cdot 30 \\
\mathrm{P}=\mathrm{NS}\end{array}$ & $3 \cdot 20 \pm 0.03^{*}$ \\
\hline & $\begin{array}{l}1722 \pm 137 \\
P<0.01\end{array}$ & $\begin{array}{l}1076 \pm 87 \\
P<0.001\end{array}$ & $2320 \pm 80 \dagger$ \\
\hline & $125 \pm 6$ & $61 \pm 4$ & - \\
\hline
\end{tabular}

$P$ values refer to differences from control values. In addition, there was a significant difference in peripheral resistance $(P<0.001)$ and cardiac index $(P<0.05)$ between normotensive and hypotensive patients.

* From Doyle et al.(1953).

†From Carey et al. (1967). significantly from a mean of $107 \cdot 5 \pm 1$ SEM $2 \cdot 1$ to $101 \cdot 1 \pm 1$ SEM $3 \cdot 1$ (paired $t$ test, $\mathrm{P}<0.001$ ).

In the 11 patients in whom it was measured during an unexplained episode of hypotension, the indirect left atrial pressure was found to be normal with a mean value of $2.2 \mathrm{mmHg}$ (range $0-7.5 \mathrm{mmHg}$ ). Assessment of left ventricular response to fluid infusion showed that in eight of these 11 the left ventricular stroke work index increased markedly after infusion of $500 \mathrm{ml}$ plasma (Fig. 2), and the systolic blood pressure rose from a mean of $63 \mathrm{mmHg}$ to $102 \mathrm{mmHg}$. Although seven of these eight patients eventually died, and four of them had between one and four further hypotensive episodes before death, in all but two of them the blood pressure responded again to volume expansion, and the conscious level in two patients showed a definite improvement after the restoration of a normal blood pressure. In three of the 11 patients there was evidence of heart failure with flat ventricular function curves (Fig. 2). The indirect left atrial pressure in these patients was higher than in the remainder before volume expansion, although values for venous pressure were similar. Two of the three had been hypotensive for more than 18 hours before investigation and had ischaemic changes on the electrocardiogram with ST depression and T-wave inversion. The third patient, who had been hypotensive for only two hours, had a normal electrocardiogram and, after a five minute infusion of isoprenaline $(10 \mathrm{mg} / \mathrm{min})$, a moderate increase in left ventricular stroke work index and blood pressure occurred (Table 3), but the heart rate rose to $160 / \mathrm{min}$. When dopamine $(0 \cdot 12 \mathrm{mg} / \mathrm{min})$ was infused for five minutes there was a greater increase in left ventricular stroke work index with a heart rate of only 110/min (Table 3). Furthermore, urine output, which had been zero for the previous four hours, increased to $50 \mathrm{ml} / \mathrm{h}$. With continuous infusion of dopamine the patient's cardiovascular status re- 

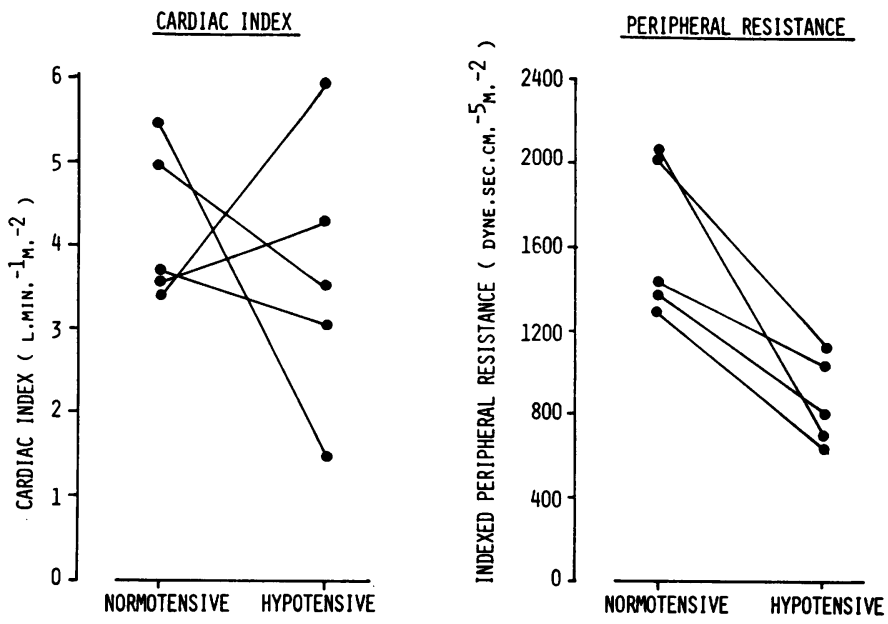

Fig. 1 The cardiac output and indexed peripheral resistance in five patients measured when normotensive and then again when hypotensive. No consistent change occurred in the cardiac index, but the indexed peripheral resistance fell in all patients with the onset of hypotension.

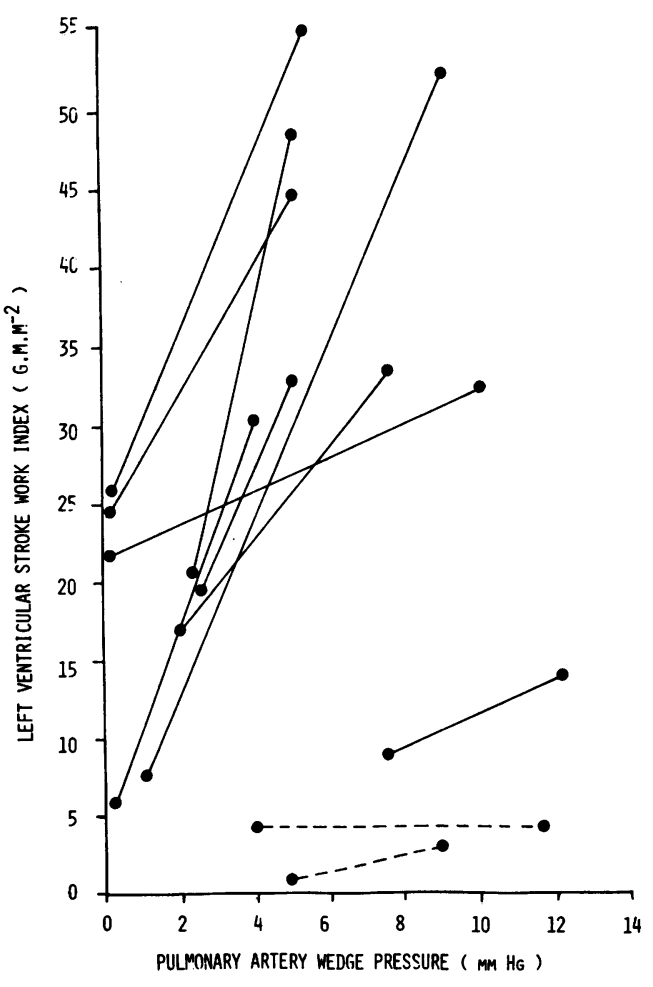

Fig. 2 Left ventricular function curves in 11 patients with unexplained hypotension. In eight patients the left ventricular stroke work index rose to over $30 \mathrm{gmm}^{-2}$ after the administration of $500 \mathrm{ml}$ plasma. Of the three in whom it did not, two (....) had been hypotensive for longer than 18 hours and had ischaemic changes on the electrocardiogram.
Table 3 Effect of plasma infusion,isoprenaline, and dopamine on cardiovascular parameters in one patient in whom blood pressure responded poorly to plasma infusion

\begin{tabular}{|c|c|c|c|c|}
\hline Treatment & $\begin{array}{l}\text { Heart } \\
\text { rate }\end{array}$ & $\begin{array}{l}\begin{array}{l}\text { Blood } \\
\text { pressure }\end{array} \\
(\mathrm{mmHg})\end{array}$ & $\begin{array}{l}\text { Indirect left } \\
\text { atrial } \\
\text { pressure } \\
(\mathrm{mmHg})\end{array}$ & $\begin{array}{l}\text { Left ventricular } \\
\text { stroke work } \\
\text { index } \\
\left(\mathrm{gmm}^{-2}\right)\end{array}$ \\
\hline \multicolumn{5}{|c|}{$500 \mathrm{ml}$ plasma } \\
\hline Before & 110 & $50 / 20$ & $7 \cdot 5$ & $8 \cdot 3$ \\
\hline & 110 & $60 / 30$ & $16 \cdot 0$ & $14 \cdot 0$ \\
\hline \multicolumn{5}{|c|}{$\begin{array}{l}\text { Isoprenaline } \\
(10 \mathrm{mg} / \mathrm{min})\end{array}$} \\
\hline Before & 105 & $65 / 40$ & $12 \cdot 5$ & $14 \cdot 0$ \\
\hline After & 160 & $100 / 40$ & 7.5 & $31 \cdot 3$ \\
\hline \multirow{2}{*}{\multicolumn{5}{|c|}{$\begin{array}{l}\text { Dopamine } \\
(120 \mathrm{mcg} / \mathrm{min})\end{array}$}} \\
\hline & 105 & $70 / 40$ & 12 & 14.0 \\
\hline After & 110 & $110 / 60$ & 10 & 56.6 \\
\hline
\end{tabular}

mained stable until his death 24 hours later from cardiac asystole.

RELATION OF UNEXPLAINED HYPOTENSION TO CARDIAC PATHOLOGY AND CEREBRAL CONING

At necropsy, which was carried out in 30 of the patients with unexplained hypotension, 13 were found to have a normal myocardium. The abnormalities in the remaining 17 consisted of subendocardial and subpericardial petechiae and haemorrhages, mild left ventricular failure, and, on microscopy, fatty infiltration. The frequency of such abnormalities was no higher than in those patients not developing unexplained episodes of hypotension, in whom nine out of 18 had an abnormal myocardium at necropsy. 
With respect to cerebral oedema and coning, 11 out of the 22 patients who had had episodes of unexplained hypotension during life and in whom the brain was examined at necropsy, had evidence of brainstem coning with temporal lobe or cerebellar herniation. By contrast, cerebral oedema of this degree was present in none of the 16 patients who had not developed unexplained hypotension during life and in whom the brain was examined at necropsy $\left(\chi^{2}=6.30, \mathrm{P}<0.02\right)$.

\section{Discussion}

The increased mortality in the patients who became hypotensive during the course of their illness is perhaps not surprising. The associated reduction in cerebral, as well as myocardial, renal, and hepatic perfusion may have resulted in secondary ischaemic damage in these organs, and in an animal model of hepatic failure we have recently demonstrated that when the systolic blood pressure falls to only $90 \mathrm{mmHg}$ there is a significant reduction in both the cerebral blood flow and the cerebral metabolic rate for oxygen (Trewby et al., 1978). An alternative explanation is that the hypotension may not in itself have affected the mortality but merely reflected a more severe underlying hepatic necrosis. The significantly longer prothrombin time in the patients with episodes of unexplained hypotension was in keeping with this explanation and suggested a greater impairment of liver function in these patients.

In the patients with unexplained hypotension the combination of a low blood pressure and a normal cardiac output suggests that inappropriate vasodilatation, rather than primary myocardial pump failure, was responsible. This was supported by the normal or low pulmonary artery wedge pressure and central venous pressure. Furthermore, the ventricular function curve was normal in seven out of 11 of the patients in whom it was measured, and in two of the three patients in whom it was abnormal myocardial damage may have occurred as a result of the prolonged hypotension.

With respect to the possible causes of this vasodilatation, the significantly slower heart rate in the patients when hypotensive than when normotensive, and the association between the unexplained hypotension and cerebral oedema with coning, suggests a central mechanism. However, not all the patients who became hypotensive had evidence of coning, and in 11 of 22 patients examined at necropsy the brain was macroscopically normal. In these patients it is possible that a metabolic insult to the vasomotor centre, not in itself of sufficient severity to cause macroscopic structural changes or cerebral oedema, could nevertheless result in damage to the vasomotor centre.
Alternatively, vasodilatation may be consequent on the appearance of vasoactive compounds in the circulation which may fail to be metabolised by the necrotic liver, or are released from it. In favour of this mechanism was the correlation found between unexplained hypotension and the severity of the hepatic necrosis as assessed by the prothrombin time. One such vasoactive compound, endotoxin, has been demonstrated in the serum of $64 \%$ of patients with fulminant hepatic failure (Wilkinson et al., 1974), and injection of endotoxin experimentally leads to the opening up of peripheral arteriovenous shunts (Liehr et al., 1975). In this respect it is of interest that intrapulmonary shunts of up to $39 \%$ of the cardiac output have been demonstrated in patients with fulminant hepatic failure with a corresponding increase in peripheral vasodilatation (Trewby et al., 1976). Vasointestinal peptide, bradykinin, and histamine could all act in a similar way. Alternatively, weak sympathetic neurotransmitters may accumulate in hepatic failure and result in a diminished peripheral resistance by competitive inhibition of noradrenaline. Octopamine is one such putative false neurotransmitter, but in a recent investigation we found the highest serum concentrations in the normotensive, and not in the hypotensive, patients (Trewby et al., 1977). This could be explained if octopamine were released from sympathetic nerve terminals along with noradrenaline and if sympathetic drive were increased in the normotensive patients but it does not suggest a causative role for octopamine in the genesis of the hypotension.

With regard to treatment, there was a satisfactory increase in left ventricular stroke work index and blood pressure in response to volume expansion in eight out of 11 patients studied. The danger of volume expansion is that it may predispose to pulmonary oedema, especially in the presence of coexistent renal failure. Although pulmonary oedema was seen on the chest radiographs of three patients, in one this had developed before the onset of hypotension, and in the other two the pulmonary artery wedge pressure was within normal limits when pulmonary oedema was first noticed, suggesting that fluid overload was not the cause of the oedema. In the few patients with evidence of myocardial failure, dopamine proved superior to isoprenaline as an inotropic agent. Experimentally, dopamine not only improves myocardial function but also results in dilatation of both splanchnic and renal vascular beds (Goldberg, 1972), and in one patient urine output increased to normal after infusion of dopamine. In two patients there was a convincing improvement in mental state when normal blood pressure had been restored. However, it might be 
more beneficial if episodes of hypotension, with all their potentially damaging consequences, could be prevented, but we are hindered by the inevitable primary role of cerebral oedema, which represents a major problem, both with respect to pathogenesis and its control by therapy, in the syndrome of fulminant hepatic failure.

This study is part of a programme of research in liver failure supported by the Medical Research Council, Smith's Charity, and the Wates' Foundation. We are grateful to the medical and nursing staff who cared for the patients and to Linda Rimmer for editorial assistance.

\section{References}

Carey, J. S., Brown, R. S., Mohr, P. A., Monson, D. O., Yao, S. T., and Shoemaker, W. C. (1967). Cardiovascular function in shock: responses to volume loading and isoproterenal infusion. Circulation, 35, 327-338.

Doyle, J. T., Wilson, J. S., Lépine, C., and Warren, J. V. (1953). An evaluation of the measurement of the cardiac output and the so-called pulmonary blood volume by the dye-dilution method. Journal of Laboratory and Clinical Medicine, 41, 29-39.

Ganz, W., and Swan, H. J. C. (1962). Measurement of blood flow by thermodilution. American Journal of Cardiology, 29, 241-246.

Gazzard, B. G., Portmann, B., Murray-Lyon, I. M., and Williams, R. (1975). Causes of death in fulminant hepatic failure and relationship to quantitative histological assessment of parenchymal damage. Quarterly Journal of Medicine, 44, 615-626.

Gazzard, B. G., Weston, M. J., Murray-Lyon, I. M., Flax, H., Record, C. O., Portmann, B., Langley, P. G., Dunlop, E. H., Mellon, P. J., Ward, M. B., and Williams, R. (1974). Charcoal haemoperfusion in the treatment of fulminant hepatic failure. Lancet, 1, 1301-1307.
Goldberg, L. I. (1972). Cardiovascular and renal actions of Dopamine: potential clinical applications. Pharmacological Reviews, 24, 1-29.

Hamilton, W. F. (1962). Measurement of the cardiac output. In Handbook of Physiology, section 2, vol. 1, p. 580. Edited by W. F. Hamilton and P. Dow. American Physiological Society: Washington, D.C.

Liehr, H., Grün, M., Thiel, H., Brunswig, D., and Rasenack, U. (1975). Endotoxin-induced liver necrosis and intravascular coagulation in rats enhanced by portacaval collatera circulation. Gut, 16, 429-436.

Ritt, D. J., Whelan, G., Werner, D. J., Eigenbrodt, E. H., Schenker, S., and Combes, B. (1969). Acute hepatic necrosis with stupor or coma. An analysis of 31 patients. Medicine (Balt.), 48, 151-172.

Rueff, B., and Benhamou, J-P. (1973). Acute hepatic necrosis and fulminant hepatic failure. Gut, 14, 805-815.

Silk, D. B. A., Hanid, M. A., Trewby, P. N., Davies, M., Chase, R. A., Langley, P. G., Mellon, P. J., Wheeler, P. G., and Williams, R. (1977). Treatment of fulminant hepatic failure by haemodialysis using a polyacrylonitrile membrane. Lancet 2, 1-3.

Trewby, P. N., Williams, R., Williams, A., and Reid, L. (1976). Intrapulmonary vascular shunts in fulminant hepatic failure. Digestion, 14, 466 (Abstract.)

Trewby, P. N., Hanid, A., Mackenzie, R. L., Mellon, P. J., and Williams, R. (1978). The effects of cerebral oedema and arterial hypotension on cerebral blood flow in an animal model of hepatic failure. (Submitted for publication.)

Trewby, P. N., Chase, R. A., Davis, M., and Williams, R. (1977). The role of the false neurotransmitter octopamine in the hypotension of fulminant hepatic failure. Clinical Science and Molecular Medicine, 52, 305-310.

Trey, C., and Davidson, C. S. (1970). The management of fulminant hepatic failure. In Progress in Liver Disease, vol 3, pp. 282-298. Edited by H. Popper and F. Schaffner. Grune and Stratton: New York.

Wilkinson, S. P., Arroyo, V., Gazzard, B. G., Moodie, H., and Williams, R. (1974). Relation of renal impairment and haemorrhagic diathesis to endotoxaemia in fulminant hepatic failure. Lancet, 1, 521-524.

Wood, P. H. (1956). Diseases of the Heart and Circulation, 2nd rev. edn., p. 178. Eyre and Spottiswoode: London. 